\title{
Challenging delivery of VLHL NS plasminogen activator inhibitor-1 by osmotic pumps in diabetic mouse: A case report
}

\author{
JERZY JANKUN

\begin{abstract}
Urology Research Center, Department of Urology, Health Science Campus, University of Toledo, Toledo, OH, USA;
Department of Clinical Nutrition, Medical University of Gdańsk, Gdańsk, Poland; Protein Research Chair, Biochemistry Department, College of Sciences, King Saud University, Riyadh 11451, Kingdom of Saudi Arabia
\end{abstract}

Received March 28, 2012; Accepted July 5, 2012

DOI: $10.3892 /$ etm.2012.639

\begin{abstract}
ALZET $^{\circledR}$ osmotic pumps are implantable devices used in animals for the continuous infusion of drugs or proteins at controlled rates from 1 day to 4 weeks. Pumps have been used successfully in a number of studies on the effects of controlled delivery of a wide range of experimental agents, independent of their properties. In the present study, use of these pumps was made in mice with diabetic nephropathy. Plasminogen activator inhibitor-1 (PAI-1) mediates diabetic nephropathy, which is characterized by the excessive accumulation of extracellular matrix (ECM) in the kidney. Disproportionate PAI-1 inactivates tissue plasminogen activator, which is one of the proteolytic enzymes in a cascade responsible for ECM remodeling in the kidney. The decrease of PAI-1 in the kidney has been shown to arrest the progression of nephropathy in experimental animals. This was achieved using inactive PAI-1R which increased the clearance of wild-type PAI-1 in order to protect net proteolytic activity and ECM clearance. However, this protein has a brief half-life in vivo, therefore, high and frequent doses are required. Thus, VLHL NS PAI-1 protein with a long half-life of over $700 \mathrm{~h}$ (Gln197Cys, Gly355Cys) inactivated by single point mutation (Arg369Ala) was used. Following the sacrifice of animals the tips of the flow moderators of the osmotic pumps in the treated animals were found to be clogged. In addition, from each pump from the treatment group, but not controls, we collected 50-150 $\mu 1$ of clear liquid containing VLHL NS PAI-1, cellular and serum proteins suggesting early pump sealing by cellular material. In conclusion, despite encouraging results obtained for the PAI-1R protein, the method of VLHL PAI-1 delivery should be ameliorated.
\end{abstract}

Correspondence to: Dr Jerzy Jankun, Urology Research Center, Department of Urology, Health Science Campus, University of Toledo, 3000 Arlington Avenue, MS 1091, Toledo, OH 43614, USA E-mail: jerzy.jankun@utoledo.edu

Key words: osmotic pump, diabetes, plasminogen activator inhibitor-1

\section{Introduction}

ALZET $^{\circledR}$ osmotic pumps are implantable pumps used for research in mice and other animals for the continuous infusion of drugs or proteins at controlled rates from 1 day to 4 weeks, without the need for external handling. These pumps are used for systemic administration by implantation subcutaneously or intraperitoneally. Pumps have previously been used in a number of studies on the effects of controlled delivery of a wide range of experimental agents, including addictive drugs, steroids, chemotherapeutic drugs, hormones, and antibodies or other proteins. It is extremely important that compounds of any molecular conformation are delivered predictably at controlled rates, independent of their properties (1-4). In the present study, the pumps were used to deliver plasminogen activator inhibitor-1 (PAI-1) to successfully reduce tumor size in SCID mouse in the past (5).

In this study, ALZET osmotic pumps were used on mice with diabetic nephropathy. Various factors have been suggested in the pathogenesis of diabetic nephropathy, including an increased PAI-1 level in plasma. PAI-1 mediates diabetic nephropathy, which is characterized by excessive accumulation of extracellular matrix (ECM) in the kidney. Excessive PAI-1 inactivates tissue plasminogen activator, which is one of the proteolytic enzymes in a cascade responsible for ECM remodeling in the kidney. A decrease of PAI-1 in the kidney has been shown to arrest the progression of nephropathy in experimental animals. This decrease was achieved using inactive PAI-1R which increased clearance of wild-type PAI-1 in order to protect net proteolytic activity and ECM clearance $(6,7)$. However, this protein has a brief half-life in vivo, therefore, high and frequent doses are required for it to be effective. VLHL NS PAI-1 (8) with a long half-life of over 700 h (Gln197Cys, Gly355Cys) inactivated by single point mutation (Arg369Ala) was therefore used (9). We hypothesized that this protein is likely to prevent nephropathy when used in the early stages of diabetes and arrest its progression in advanced stages of this disease.

VLHL NS PAI-1 was loaded into osmotic pumps to deliver protein over a 2 -week period in Dock $7^{\mathrm{m}}+/+$ Lepr $^{\mathrm{db}}$ diabetic mice to observe whether it had any effects on diabetes. All pumps containing VLHL NS PAI-1 were found to be clogged and the majority of the buffer with the active ingredient 
Table I. Proteins detected in the SDS-PAGE gel.

\begin{tabular}{|c|c|c|c|c|}
\hline UniProt \# & Protein name & Probability & Line on gel & $\begin{array}{c}\text { Relative } \\
\text { concentration }\end{array}$ \\
\hline A0AUV1 & Histone $\mathrm{H} 2 \mathrm{~A}$ & 0.999 & 1,2 & \\
\hline A1E281 & $\beta$-actin & 0.999 & 2 & \\
\hline A2AL35 & Gelsolin, isoform CRA_b & 0.999 & 2 & \\
\hline A2CG44 & MAD homolog 3 (Drosophila) & 0.999 & 1,2 & \\
\hline A5JUZ1 & Ubiqutin subunit 1 & 0.994 & 1,2 & \\
\hline A8DUK0 & Hbbt1 & 0.999 & 1,2 & \\
\hline A8DUV3 & $\alpha$-globin & 0.999 & 2 & \\
\hline B2RSN3 & Tubulin, $\beta$ 2B & 0.999 & $1,4,5$ & High \\
\hline B7U582 & Heat shock protein $70-2$ & 0.999 & $1,2,3$ & \\
\hline B7ZNJ1 & Fn1 protein & 0.999 & 1 & \\
\hline B8JJM3 & Complement factor B & 0.999 & 2 & \\
\hline D3YTY9 & Putative uncharacterized protein Kng1 & 0.999 & 3 & \\
\hline D3YV43 & Putative uncharacterized protein Rps3 & 0.999 & 4 & \\
\hline D3YVC1 & Putative uncharacterized protein Rps2 & 0.995 & 4 & \\
\hline D3YVF4 & Putative uncharacterized protein Rps14 & 0.999 & 4 & \\
\hline D3YW44 & Putative uncharacterized protein Gm5121 & 0.999 & 4 & \\
\hline D3YW52 & Putative uncharacterized protein Pzp & 0.999 & 1,2 & High \\
\hline D3YYR8 & Putative uncharacterized protein Trf & 0.999 & 2,3 & \\
\hline D3Z0D8 & Putative uncharacterized protein Rrm2 & 0.999 & 4 & \\
\hline D3Z3P6 & Putative uncharacterized protein ENSMUSP00000032206 & 0.994 & 1 & \\
\hline D3Z451 & Putative uncharacterized protein $\mathrm{Gm} 4931$ & 0.999 & 3 & \\
\hline D3Z6U8 & Putative uncharacterized protein Fmr1 & 0.999 & 4 & \\
\hline P05121 & HUMAN plasminogen activator inhibitor 1 & 0.999 & $1,2,3,4,5$ & Very high \\
\hline Q14AS7 & Serine (or cysteine) peptidase inhibitor, clade A, member $3 \mathrm{C}$ & 0.999 & 3 & \\
\hline Q2F3J4 & Truncated ceruloplasmin & 0.999 & 2 & \\
\hline Q3KQQ4 & Serpina1a protein & 0.999 & 3 & High \\
\hline Q3TGR2 & Putative uncharacterized protein & 0.999 & 1 & \\
\hline Q3TII3 & Elongation factor $1-\alpha$ & 0.999 & 1,4 & \\
\hline Q3TX45 & Gene name, Apoe; putative uncharacterized protein & 0.999 & 1 & \\
\hline Q3U9U3 & Gene name, Tubb6; putative uncharacterized protein & 0.999 & $1,4,5$ & High 4,5 \\
\hline Q3UBS3 & Gene name, Hp; putative uncharacterized protein & 0.999 & 2 & \\
\hline Q3UID0 & Gene name, Smarcc2; putative uncharacterized protein & 0.999 & 1 & \\
\hline Q3UKP2 & Gene name, Hpx; putative uncharacterized protein & 0.999 & 2,3 & High 3 \\
\hline Q3UKX6 & Gene name, Apoa2; putative uncharacterized protein & 0.999 & 1,2 & \\
\hline Q3V2E0 & Gene name, Try5; putative uncharacterized protein & 0.999 & 3 & \\
\hline Q3V2G1 & Gene name, Apoa1; putative uncharacterized protein & 0.999 & 1,2 & High 2 \\
\hline Q543J5 & Serine (or cysteine) peptidase inhibitor, antithrombin & 0.999 & 3 & Very high \\
\hline Q546G4 & Serum albumin & 0.999 & $1,2,3,4,5$ & \\
\hline Q58E61 & Igh protein & 0.999 & 1 & \\
\hline Q5FW91 & Tubulin, $\alpha 3 \mathrm{~B}$ & 0.999 & $1,4,5$ & High \\
\hline Q5M9K1 & Transthyretin & 0.999 & 2,3 & \\
\hline Q65ZL8 & VH7183-DSP2-JH3-CH1 protein & 0.999 & 1 & \\
\hline Q80XP1 & Complement component 3 & 0.999 & 2 & \\
\hline Q810I7 & Apoa4 protein & 0.999 & 1,2 & \\
\hline Q8C4B1 & Gene name, Larp1b; putative uncharacterized protein & 0.999 & 1 & \\
\hline Q8K051 & Trip12 protein & 0.999 & 1 & \\
\hline Q8VC41 & Serpina1d protein & 0.999 & 2,3 & High 3 \\
\hline Q9CZQ0 & Gene name, Nudt21; putative uncharacterized protein & 0.999 & 2,3 & \\
\hline Q9JHV2 & Lectin-related NK cell receptor LY49T & 0.992 & 2 & \\
\hline Q9Z1R9 & Trypsinogen 16 & 0.994 & 1,2 & \\
\hline
\end{tabular}

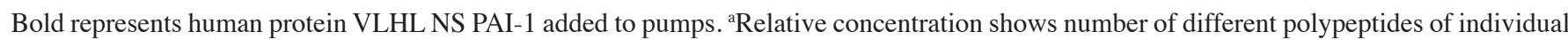
protein detected by mass spectrometry. 
remained within the pumps while the control pumps contained little, if any, buffer. Analyses of proteins in the pumps suggests that the pumps were clogged by cellular material early in the experiment.

\section{Materials and methods}

VLHL NS PAI-1. VLHL NS PAI-1 was expressed and purified as reported previously (9). VLHL NS PAI-1 was in an active conformation with traces of VLHL NS PAI-1 in latent conformation. The purity of protein was determined as high as $+95 \%$ by densitometry (9).

Animals. Animals were purchased from The Jackson Laboratory (TJL; Bar Harbor, ME, USA) and maintained according to TJL recommendations. Mice homozygous for the diabetes spontaneous mutation $\left(\mathrm{Lepr}^{\mathrm{db}}\right)$, strain name BKS. Cg-Dock $7^{\mathrm{m}}+/+$ Lepr $^{\mathrm{db}} / \mathrm{J}(\mathrm{db} / \mathrm{db})$, become obese at 3-4 weeks of age. Elevation of plasma insulin begins at 10-14 days and elevation of blood sugar at 4-8 weeks. Homozygous mutant mice are polyphagic, polydipsic and polyuric. The severity of disease on this genetic background leads to an uncontrolled rise in blood sugar, severe depletion of the insulin-producing $\beta$-cells of the pancreatic islets and death by 10 months of age. Exogenous insulin fails to control blood glucose levels and gluconeogenic enzyme activity increases. Peripheral neuropathy and myocardial disease are observed and wound healing is delayed. An increased amount of PAI-1 in kidney and in animal serum was also detected $(6,7)$.

The $\mathrm{db} / \mathrm{db}$ mouse is the model that develops abnormalities in renal morphology and function that parallel those in human nephropathy of type 2 diabetes (6). Following uninephrectomy at the 8th week of age, a greatly accelerated development and progression of diabetic nephropathy was reported. Increased levels of glucose were observed between weeks 8 and 20 with an increase of PAI-1 in kidney tissue. Uninephrectomized diabetic $\mathrm{db} / \mathrm{db}$ mice developed nephropathy by 20 weeks of age, manifested by expansion of the mesangium and significant albuminuria $(6,7)$.

At 20 weeks, animals had an intra-abdominal osmotic pump implanted to administer the buffer (control group) or VLHL NS PAI-1 (treatment group). The pumps were purchased from Durect Corporation ALZET Osmotic Pumps (Cupertino, CA, USA). The treatment group mice $(n=6)$ were implanted with ALZET pump \#2002 filled with $200 \mu \mathrm{l}$ of VLHL NS PAI-1 (350 $\mu \mathrm{g}$ of protein). These pumps are designed to deliver $0.5 \mu \mathrm{l} / \mathrm{h}$ over 16 days at a total of $\sim 200 \mu \mathrm{l}$. Similarly, the control group mice $(n=6)$ were implanted with ALZET pump \#1002 filled with $100 \mu \mathrm{l}$ of PBS. These pumps are designed to deliver $0.25 \mu \mathrm{l} / \mathrm{h}$ over 16 days for a total of $\sim 100 \mu \mathrm{l}$. At 22 weeks of age (14 weeks post-uninephrectomy), the two groups of animals were placed in metabolic cages for $24 \mathrm{~h}$ to collect 24 -h urine samples. At the end of $24 \mathrm{~h}$, blood samples were collected via cardiac puncture under anaesthesia and sacrificed via exsanguination.

Mass spectrometry-based proteomic analysis. The mass spectrometry-based proteomic analysis was performed at the Proteomics Resource Facility, Department of Pathology (Ann Arbor, MI, USA) using multidimensional proteomic

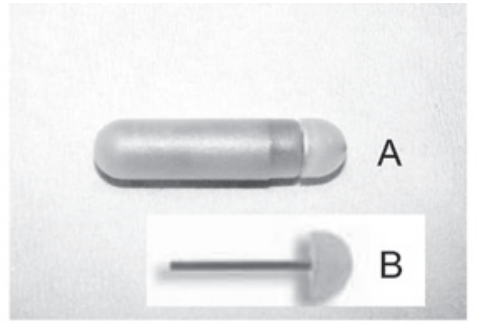

Figure 1. (A) Fully assembled ALZET ${ }^{\circledR}$ osmotic pump; (B) flow modulator.

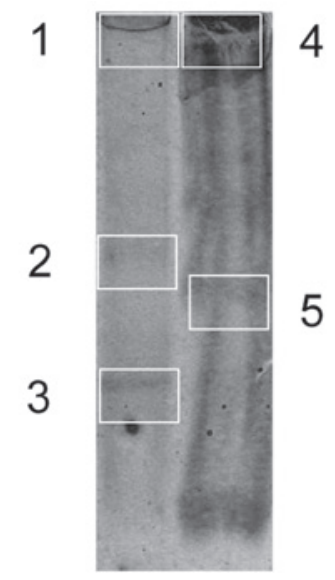

Figure 2. SDS-PAGE gel of liquid collected from two different pumps and approximate position of cuts analyzed by mass spectrometry. Each of the gel cuts (1-5) was analyzed separately by mass spectrometry.

identification technology. The data were searched against a mouse database appended with human PAI-1 (UniProt accession, \#P05121).

\section{Results and discussion}

At the end of the experiments, the mice showed signs of severe obesity and severe diabetes (data not shown). After sacrifice it was observed that the tips of the flow moderator of osmotic pumps in the treated animals were clogged by yellow cell material. The control group was free of obstructing material. On close examination it was noted that the tip plug was 1- to 3-mm long and difficult to remove from the flow modulator (Fig. 1). In addition, in each pump from the treatment group we collected 50-150 $\mu \mathrm{l}$ of clear liquid. Almost no liquid remained in the pumps of the control group. The collected liquid from two pumps of the treatment group was analysed by SDS-PAGE electrophoresis. As shown in Fig. 2, numerous protein bands were detected. Randomly chosen samples were cut from the SDS-PAGE gel and sent for protein identification. Numerous proteins were detected in various locations.

The dominant protein was VLHL NS PAI-1 identified as wild-type human PAI-1 (Table I). This protein was detected in all bands suggesting multiple complexes with other proteins. It is also proof that VLHL NS PAI-1 remains in the pump, i.e., it was delivered as intended and the pumps were blocked early. The other elevated proteins were identified as tubulin, serpina 1a, serpina 1d and serum albumin. These, and less abundant proteins, were of circulatory and cellular origin 
(Table I). ALZET ${ }^{\circledR}$ pumps operate at an osmotic pressure difference between a compartment within the pump and the tissue environment in which the pump is implanted may reach at least $0.5 \mathrm{~atm}(10)$. Thus, the stopper was relatively rigid and could be made from adipose tissue abundant in the intra-abdominal cavity of diabetic mice. Our initial hypothesis was that VLHL NS PAI-1 attracted the cells into the tip of the flow modulator of the osmotic pump. Plasminogen activator inhibitor has been reported to be a motility factor $(11,12)$ and adhesion factor, however, inactive PAI-1 [P14 mutant (Thr333Arg)] failed to enhance adhesion (13). Thus, the phenomenon remains unexplained, and a literature search failed to yield any studies on similar incidents. Additionally, the manufacturer was not aware of such incidents.

\section{Acknowledgements}

This study was supported by grants from Stranahan Endowment Fund for Oncological Research and PharmaIP, LCC.

\section{References}

1. Babin MC, Ricketts K, Skvorak JP, Gazaway M, Mitcheltree LW and Casillas RP: Systemic administration of candidate antivesicants to protect against topically applied sulfur mustard in the mouse ear vesicant model (MEVM). J Appl Toxicol 20 (Suppl 1): S141-S144, 2000.

2. Buffelli M, Busetto $G$ and Cangiano A: The use of in vivo direct drug application to assess neural regulation of muscle properties. J Neurosci Methods 106: 113-120, 2001.

3. Knedla A, Riepl B, Lefèvre S, et al: The therapeutic use of osmotic minipumps in the severe combined immunodeficiency (SCID) mouse model for rheumatoid arthritis. Ann Rheum Dis 68: 124-129, 2009.
4. Tejeda M, Gaal D, Hullán L, et al: Continuous administration of the somatostatin structural derivative /TT-232/ by subcutaneously implanted osmotic pump improves the efficacy and potency of antitumor therapy in different mouse and human tumor models. Anticancer Res 28: 2769-2774, 2008.

5. Swiercz R, Keck RW, Skrzypczak-Jankun E, Selman SH and Jankun J: Recombinant PAI-1 inhibits angiogenesis and reduces size of LNCaP prostate cancer xenografts in SCID mice. Oncol Rep 8: 463-470, 2001

6. Huang Y, Border WA, Lawrence DA and Noble NA: Mechanisms underlying the antifibrotic properties of noninhibitory PAI-1 (PAI-1R) in experimental nephritis. Am J Physiol Renal Physiol 297: F1045-F1054, 2009.

7. Huang Y, Border WA, Yu L, Zhang J, Lawrence DA and Noble NA: A PAI-1 mutant, PAI-1R, slows progression of diabetic nephropathy. J Am Soc Nephrol 19: 329-338, 2008.

8. Chorostowska-Wynimko J, Swiercz R, Skrzypczak-Jankun E, Wojtowicz A, Selman SH and Jankun J: A novel form of the plasminogen activator inhibitor created by cysteine mutations extends its half-life: relevance to cancer and angiogenesis. Mol Cancer Ther 2: 19-28, 2003.

9. Jankun J, Aleem AM, Specht Z, et al: PAI-1 induces cell detachment, downregulates nucleophosmin (B23) and fortilin (TCTP) in LnCAP prostate cancer cells. Int J Mol Med 20: 11-20, 2007.

10. Hjorts $\varnothing$ E, Jordening H, Jensen H, Munck O and Qvist J: The function of a continuous medication system in subatmospheric pressure environment. Scand J Clin Lab Invest 46: 293-295, 1986.

11. Kutz SM, Hordines J, McKeown-Longo PJ and Higgins PJ: TGF- $\beta 1$-induced PAI-1 gene expression requires MEK activity and cell-to-substrate adhesion. J Cell Sci 114: 3905-3914, 2001.

12. Samarakoon R, Higgins SP, Higgins CE and Higgins PJ: TGF- $\beta 1$-induced plasminogen activator inhibitor-1 expression in vascular smooth muscle cells requires pp60(c-src)/ EGFR(Y845) and Rho/ROCK signaling. J Mol Cell Cardiol 44: 527-538, 2008.

13. Palmieri D, Lee JW, Juliano RL and Church FC: Plasminogen activator inhibitor-1 and -3 increase cell adhesion and motility of MDA-MB-435 breast cancer cells.J Biol Chem 277: 40950-40957, 2002. 